\title{
Drug Profile and Therapeutic Adherence of African-Brazilians with Apparent Resistant Hypertension
}

Pedro Henrique Andrade Araújo Salvatore Barletta, ${ }^{1}$ Júlia Lasserre Moreira, ${ }^{2}{ }^{\circledR}$ Vitor Fernandes de Almeida, ${ }^{2}$ - Mateus Andrade Bomfim Machado, ${ }^{2 @}$ Breno Lima de Almeida, ${ }^{2}{ }^{\circledR}$ Tayla Samanta Silva dos Santos, ${ }^{\circledR}$ Yana Mendonça Nascimento, ${ }^{2}$ Thaise Almeida Silva, ${ }^{\circledR}{ }^{\circledR}$ Roque Aras, $^{2}{ }^{\circledR}$ Cristiano Macedo ${ }^{2}{ }^{\circledR}$

Faculdade de Medicina da Bahia da Universidade Federal da Bahia, 'Salvador, BA - Brazil. Hospital Universitário Professor Edgard Santos (HUPES), ${ }^{2}$ Salvador, BA - Brazil.

\section{Abstract}

Background: Resistant hypertension (RH) is manifested by the presence of blood pressure values resistant to antihypertensive therapy. $\mathrm{RH}$ is highly prevalent among black individuals, increasing cardiovascular risk in this population and requiring effective control of this comorbidity.

Objectives: To investigate the medication profile and therapeutic adherence in black people with apparent RH.

Methods: This is a cross-sectional study, with a convenience sample of individuals with apparent RH. Data were obtained from medical records. Therapeutic adherence was assessed using the Morisky Therapeutic Adherence Scale of 8 items (MMAS-8) and statistical analysis was performed using the SPSS, version 23. Significance was set at $\mathrm{p}<0.05$.

Results: Of the 120 individuals, 90 (75\%) were women and 72 (60\%) were black. Mean SBP was 153.09 (SD 25.59) $\mathrm{mm} \mathrm{Hg}$ and mean DBP, 90.82 (SD 16.91) $\mathrm{mm} \mathrm{Hg}$, with a statistical difference in relation to the target pressure for SBP. Regarding the medication profile, $79.2 \%$ of the individuals used the recommended regimen for RH (ACEI / $\mathrm{ARB}+$ Diuretic + CCB), with the fourth most used drug being beta-blockers. The average score in MMAS- 8 was 6.62 (SD 1.38) points, with $19.2 \%, 50.0 \%$, and $30.8 \%$ showing low, medium, and high adherence, respectively.

Conclusions: It was evidenced that two-thirds of the individuals did not have high therapeutic adherence and not all used the ideal regimen for the management of RH, nor full doses. Thus, most individuals were probably affected by pseudoresistance, which was initially diagnosed as apparent RH. (Int J Cardiovasc Sci. 2021; 34(3):300-306)

Keywords: Hypertension; African Continental Ancestry Group; Medication Adherence; Antihipertensive Agents; Blood Pressure; Drug Resistance.

\section{Introduction}

Systemic hypertension ( $\mathrm{SH}$ ) is an important risk factor for cardiovascular events, especially stroke, which justifies the relevance of its proper management. In a meta-analysis conducted by Sarki et al., ${ }^{1}$ the results showed a prevalence of $32.3 \%$ of $\mathrm{SH}$, and Latin America was as one of the regions with the highest estimates (39.1\%). ${ }^{1}$ According to data from the American Heart Association, specifically in the African-American population, the prevalence of $\mathrm{SH}$ reaches $44.9 \%$ for black men, and $46.1 \%$ for black women. ${ }^{2}$ A higher prevalence of $\mathrm{SH}$ in blacks was also identified in Brazilian studies. ${ }^{3-5}$

Despite this high prevalence, pressure control is achieved in most cases with the appropriate choice of antihypertensive drugs. ${ }^{6}$ However, still $9-18 \%$ of individuals with $\mathrm{SH}$ have blood pressure levels resistant to pharmacological treatment, which characterizes resistant hypertension $(\mathrm{RH}){ }^{6-8}$ 
RH is defined as uncontrolled in-office blood pressure $(\geq 140 / 90 \mathrm{~mm} \mathrm{Hg}$ ) despite the use of 3 or more antihypertensive drugs in adequate doses, preferably including a diuretic. ${ }^{6-9}$ Hypertension is also considered resistant when pressure control is obtained $(<140 / 90$ $\mathrm{mm} \mathrm{Hg}$ ), but only with the use of 4 or more drugs. ${ }^{6,7,9}$ In addition to the higher prevalence of RH in the black population, African-origin patients tend to have pressure levels that are more resistant to treatment.,10

However, it is worth mentioning that for the definitive diagnosis of true $\mathrm{RH}$, it is necessary to thoroughly check the patient's therapeutic adherence, since pseudoresistance is often due to poor adherence and / or inadequate therapeutic regimen..$^{6-8,11}$ In situations where the patient presents only blood pressure criteria and those referring to the number of antihypertensive drugs for the diagnosis of $\mathrm{RH}$, but there is no exclusion of pseudoresistance after systematic verification of therapy and adherence, the diagnosis is of apparent resistant hypertension (apparent $\mathrm{RH}$ ). ${ }^{9}$

Thus, in view of the morbidity and mortality associated with $\mathrm{SH}$ and the importance of an effective blood pressure control, we decided to investigate the drug profile and therapeutic adherence of black people with the diagnosis of apparent RH.

\section{Methods}

This is a cross-sectional descriptive study, which used a non-probabilistic convenience sample of black individuals who attended a reference outpatient clinic for the treatment of RH. Data were obtained from interviews and physical examinations, as well as the collection of information from medical records, using a standardized form approved by the Research Ethics Committee. Study participants signed a free and informed consent form, and were admitted based on the demand for assistance, as they went to the clinic for follow-up visits, from February 2014 to September 2017.

The individuals completed the questionnaire about life habits, medical history, therapeutic scheme used, and adherence to the proposed therapy while seated before blood pressure measurement. The individuals were instructed to empty their bladder before the measurement. Those who had ingested caffeinated drinks, smoked, or made physical effort, had their blood pressure measured in a minimum interval of 30 minutes.

After this initial resting moment, blood pressure was measured using a digital sphygmomanometer (Omron
Healthcare, BP785). The patient's bare arm was supported at the level of his precordium and the cuff was positioned $3 \mathrm{~cm}$ above the cubital fossa. For obese patients, the large size cuff was used (Omron Healthcare, HEMCL24). Measurements were performed on both upper limbs, with an interval of 1 minute between them; the measurement with the highest mean arterial pressure [ $(2 \times$ diastolic blood pressure + systolic blood pressure $)$ /3] was considered for record.

Information about the pharmacological prescription of each individual was obtained from medical records. Serum potassium $(\mathrm{K}+)$ and serum creatinine $(\mathrm{Cr})$ levels were also obtained from medical records, for analysis of possible justification for not using drugs known to induce hyperkalemia.

The study included self-declared black or brown individuals who used 3 or more antihypertensive drugs, with pressure control not obtained, that is, systolic blood pressure (SBP) $\geq 140 \mathrm{~mm} \mathrm{Hg}$ and / or diastolic blood pressure (DBP) $\geq 90 \mathrm{~mm} \mathrm{Hg}$; or who used 4 medications or more, with pressure control (SBP $<140 \mathrm{~mm} \mathrm{Hg}$ and DBP $<90 \mathrm{~mm} \mathrm{Hg}$ ). Because this study assesses only the pressure criteria for the diagnosis of $\mathrm{RH}$, individuals at the time of admission to the study were considered to have apparent $\mathrm{RH} .{ }^{9}$

Those with uncontrolled blood pressure even when using 5 or more antihypertensive drugs were classified as having Refractory Arterial Hypertension.

The Morisky Medication Adherence Scale of 8 items (MMAS-8) was used to assess adherence to the prescribed pharmacological treatment. Individuals with scores of 8 , $7-6$ and $\leq 5$ were classified as having high, moderate, and low therapeutic adherence, respectively.

\section{Statistical Analysis}

Statistical analysis was performed using SPSS, version 23.0. Categorical variables were presented using absolute and relative frequencies, while continuous variables were presented using means and standard deviations. The investigation of associations was conducted using the calculation of chi-square $\left(\chi^{2}\right)$ and prevalence ratio (PR). The Kolmogorov-Smirnov test was used to certify the normality of the data distribution. The comparison of means was performed using Student's t test for independent samples. The mean blood pressure values obtained were compared with the target blood pressure levels of 140/90 $\mathrm{mm} \mathrm{Hg}$ using the one sample $\mathrm{t}$ test. Similarly, the averages of the daily doses of the 
antihypertensive drugs used were compared with the maximum doses of each drug, also using the one sample $t$ rest. Significance was established at $p<0.05$.

\section{Results}

A total of 120 individuals were included in the study, whose characterization was shown in Table 1 . The mean SBP was higher than the target SBP of $140 \mathrm{~mm} \mathrm{Hg}(\mathrm{t}$ $[119]=5.603$ and $p<0.05)$, while there was no statistical difference between the mean DBP and the target DBP of $90 \mathrm{~mm} \mathrm{Hg}(\mathrm{t}[119]=0.529$ and $\mathrm{p}=0.598)$ (Table 1$)$.

Regarding the medication profile (Table 2), the mean amount of oral antihypertensive drugs used by each individual was 4.71 (SD, 1.08). In addition, $79.2 \%$ of the individuals used the ACEI / ARB + Diuretic + CCB therapeutic regimen. As shown in Table 2, there was a statistical difference between the average doses of the drugs used and the full doses of these drugs. Among these individuals, considering those who needed 4 drugs or more, $82.4 \%$ used some beta-blocker, and $49.5 \%$ used spironolactone (Figure 1). The mean of $[\mathrm{K}+]$ of those who did not use spironolactone was 4.32 (SD 0.72) $\mathrm{mmol} / \mathrm{L}$ and of those who did, 4.49 (SD 0.54) $\mathrm{mmol} / \mathrm{L}$, with no statistical difference ( $\mathrm{t}$ [91 ] $=-1.305, \mathrm{p}=0.195)$. The creatinine means among those who did not use spironolactone and those who did it were, respectively, 1.092 (SD 0.468) mg / dL and 1.095 (SD 0.276) mg / dL, with no statistical difference $(t[93]=-0.049, p=0.961)$.

\begin{tabular}{lc}
\hline \multicolumn{2}{l}{ Table $\mathbf{1}$ - Characterization of the sample } \\
\hline $\mathbf{N}$ & $\mathbf{1 2 0}$ \\
\hline Sex & $90(75 \%)$ \\
\hline Female & $30(25 \%)$ \\
\hline Male & $63.07 \pm 11.36$ \\
\hline Age (years) & $72(60 \%)$ \\
\hline Race/color & $48(40 \%)$ \\
\hline Black & $153.09 \pm 25.59$ \\
\hline Brown & $90.82 \pm 16.91$ \\
\hline Blood pressure & \\
\hline Mean SBP (mm Hg) & \\
\hline Mean DBP (mm Hg)
\end{tabular}

A total of $34.2 \%$ of individuals met the criteria for Refractory Hypertension. ${ }^{9}$ Of these, $34.1 \%$ did not use spironolactone, and $53.7 \%$ did not use the combination of chlorthalidone and spironolactone.

Regarding therapeutic adherence, the mean score on the MMAS-8 scale was 6.62 (SD 1.38) points, and the percentage of individuals with low therapeutic adherence was $19.2 \%$; moderate adherence, $50.0 \%$; and high adherence, $30.8 \%$ (Table 3 ). Comparing the groups of high and low therapeutic adherence, being a man was associated with better adherence $\left(\chi^{2}(1)=4.266[p=0.039]\right.$ and PR $=1.524$ [95\% CI $1.055-2.200]$ ]). There was no statistically significant difference between the mean age and the quantity of drugs used in these groups $(t(58)=-$ $1.330[p=0.189]$ and $t(58)=-0.372[p=0.711]$, respectively).

Although the mean pressure levels in the group with high therapeutic adherence were lower compared to the group with low adherence, there was no statistically significant difference $(t(58)=0.809$ and $p=0.422$ for mean $\mathrm{SBP}$ and for mean DBP, $\mathrm{t}(61)=0.810 ; \mathrm{p}=0.421$ ).

\section{Discussion}

Regarding the diagnosis of $\mathrm{RH}$, it is imperative to rule out potential causes for the difficult control of blood pressure, highlighting the inappropriate choice of antihypertensives, poor therapeutic adherence, the effect of white coat hypertension, and secondary hypertension..$^{6-8}$

For the treatment of $\mathrm{RH}$, the recommended therapeutic regimen should include oral antihypertensive drugs with complementary pharmacodynamics. With this, as an ideal therapy, treatment with 3 drugs is recommended, including a thiazide or thiazide-type diuretic (preferably chlorthalidone), a blocker of the renin-angiotensinaldosterone system (ARB or ACEI) and a dihydropyridine calcium channel blocker (CCB), in full tolerated doses and at appropriate intervals. ${ }^{8,12,13}$ It was observed that $79.2 \%$ of the individuals used this triple therapy. Despite this, the mean SBP verified was greater than $140 \mathrm{~mm} \mathrm{Hg}$. This may have happened due to not using the full doses of ACEI / ARB and CCB in a statistically significant way.

Tu et al., ${ }^{14}$ demonstrated that blood pressure levels in black people would be more sensitive to the effects of aldosterone. ${ }^{14}$ Other studies have shown higher plasma levels of aldosterone in black people. ${ }^{15,16}$ Given these facts, knowing that primary hyperaldosteronism is imputed in the genesis of $\mathrm{RH}_{,}^{6,8}$ it is reasonable to understand the importance of using aldosterone antagonists in the 
Table 2 - Antihypertensive drugs and percentage of use in the sample

\begin{tabular}{|c|c|c|}
\hline Drug & $\begin{array}{l}\text { Percentage of individuals } \\
\text { using the drug }\end{array}$ & $\begin{array}{l}\text { Average of daily doses compared to the maximum doses of } \\
\text { each drug }(\mathrm{mg})^{1}\end{array}$ \\
\hline \multicolumn{3}{|l|}{ Diuretic } \\
\hline Hydrochlorothiazide & $48.3 \%$ & $25.00 \pm 0.00^{2}$ \\
\hline Spironolactone & $47.5 \%$ & $30.26 \pm 10.28(\mathrm{p}<0.05)$ \\
\hline Chlorthalidone & $45 \%$ & $24.54 \pm 2.38(\mathrm{p}=0.159)$ \\
\hline Furosemide & $11.7 \%$ & $42.86 \pm 10.69(\mathrm{p}<0.05)$ \\
\hline \multicolumn{3}{|l|}{ ACEI/ARB } \\
\hline Losartan & $65.8 \%$ & $94.94 \pm 17.16(\mathrm{p}=0.011)$ \\
\hline Enalapril & $25 \%$ & $36.00 \pm 8.14(\mathrm{p}=0.012)$ \\
\hline Captopril & $4.2 \%$ & $90.00 \pm 54.77(\mathrm{p}=0.07)$ \\
\hline \multicolumn{3}{|l|}{ Beta-blocker } \\
\hline Carvedilol & $36.7 \%$ & $45.17 \pm 10.52(p=0.004)$ \\
\hline Atenolol & $21.8 \%$ & $70.19 \pm 29.17(\mathrm{p}<0.05)$ \\
\hline Propranolol & $9.2 \%$ & $90.91 \pm 36.18(\mathrm{p}<0.05)$ \\
\hline Nebivolol & $7.2 \%$ & $5.56 \pm 1.67(p<0.05)$ \\
\hline Metoprolol & $5 \%$ & $100.00 \pm 54.77(\mathrm{p}=0.07)$ \\
\hline \multicolumn{3}{|l|}{ CCB } \\
\hline Amlodipine & $70.8 \%$ & $8.56 \pm 2.33(\mathrm{p}<0.05)$ \\
\hline Nifedipine & $12.5 \%$ & $41.67 \pm 15.08(\mathrm{p}<0.05)$ \\
\hline \multicolumn{3}{|c|}{ Alpha-2-agonist } \\
\hline Clonidine & $36.3 \%$ & $0.27 \pm 0.16(p<0.05)$ \\
\hline \multicolumn{3}{|l|}{ Vasodilator } \\
\hline Hydralazine & $17.5 \%$ & $147.62 \pm 79.41(p=0.892)$ \\
\hline
\end{tabular}

therapeutic regimen of black patients, as revealed by Saha et al.,17 when demonstrating that treatment with amiloride or spironolactone may provide an additional reduction in blood pressure in blacks already receiving conventional antihypertensive therapy. ${ }^{17}$ In the present study, considering those who needed 4 drugs or more, only $49.5 \%$ used spironolactone, even without plausible justification for not using it. This fact may have contributed to the high mean of SBP.

In fact, robust studies indicate that spironolactone is preferably the fourth drug to be added to the triple ARB / $\mathrm{ACE}+\mathrm{CCB}+$ thiazide diuretic regimen in the treatment of RH. ${ }^{12,13,18}$ It is noteworthy that the PATHWAY-2 study, which demonstrated the superiority of spironolactone as the fourth antihypertensive agent, compared to doxazosin and bisoprolol, based on the reduction of home SBP. ${ }^{19}$ Based on this and the superiority of chlorthalidone over hydrochlorothiazide, ${ }^{20}$ the most recent guidelines of the American Heart Association started to define Refractory Hypertension as the failure to control blood pressure, despite the use of at least 5 antihypertensive agents of different classes, including a long-acting thiazide-type diuretic, such as chlorthalidone, and a mineralocorticoid receptor antagonist, such as spironolactone. ${ }^{12}$ 


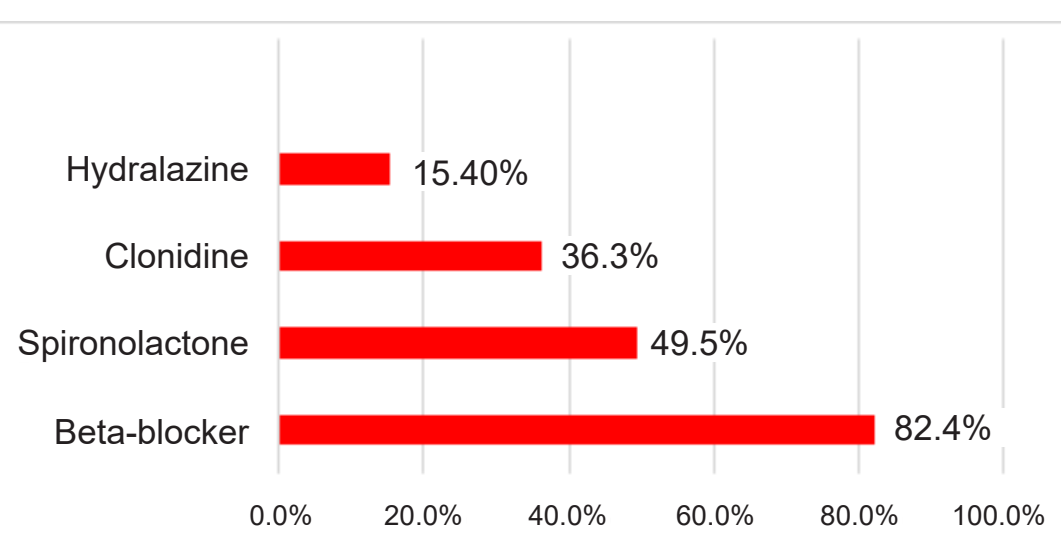

Figure 1 - Frequency of drugs added to the ACEI/ARB + CCB + DIU regimen

Table 3 - Characterization of groups according to therapeutic adherence

\begin{tabular}{lccc}
\hline & Low adherence & Moderate Adherence & High adherence \\
Relative frequency & $19.2 \%$ & $50.0 \%$ & $30.8 \%$ \\
\hline Women & $82.6 \%$ & $83.3 \%$ & $56.76 \%$ \\
\hline Men & $17.4 \%$ & $16.7 \%$ & $43.24 \%$ \\
\hline Mean age (years) & $65.74 \pm 12.48$ & $62.67 \pm 12.23$ & $62.05 \pm 8.96$ \\
\hline Mean quantity of OAH & $4.78 \pm 1.00$ & $4.70 \pm 1.02$ & $4.68 \pm 1.13$ \\
\hline Mean SBP (mm Hg) & $156.67 \pm 28.40$ & $152.98 \pm 25.25$ & $151.04 \pm 24.80$ \\
\hline Mean DBP (mm Hg) & $91.87 \pm 18.13$ & $91.91 \pm 17.73$ & $88.39 \pm 14.84$ \\
\hline OAH: oral antihypertensive; SBP: systolic blood pressure; DBP: diastolic blood pressure & & \\
\hline
\end{tabular}

Considering this most current definition of refractory hypertension, in this study, $53.7 \%$ of the individuals who met the criteria of the 7th Brazilian Directive on Arterial Hypertension for Refractory Hypertension would not be seen as having pressure levels refractory to treatment. These data reveal, once again, the importance of ensuring that the medication regimen is the recommended regimen, before establishing the diagnosis of true $\mathrm{RH}$.

On the other hand, chlorthalidone, an important medication for the control of $\mathrm{RH}$, is not included in the list of Essential Medicines of the Brazilian public Unified Health System. ${ }^{21}$ In a society where lowincome individuals are mostly black and depend on the public Health System, ${ }^{22,23}$ it is difficult to assess what is the real responsibility of the genetic background in the development of $\mathrm{RH}$, given the socioeconomic issues involved.
Regarding therapeutic adherence, Rajpura et al. ${ }^{24}$ used the 4-item Morisky scale to assess how the perception of SAH and drug therapy influences therapeutic adherence, finding a $18.8 \%$ prevalence of high adherence, $47 \%$, moderate adherence, and 34.2\% low adherence. ${ }^{24}$

Morisky et al., ${ }^{25}$ In the MMAS-8 validation study, observed that $15.9 \%$ of the study sample had high adherence, $52.0 \%$ moderate adherence, and $32.1 \%$ low adherence. ${ }^{25}$ In comparison with the studies cited, the present study revealed a lower prevalence of low therapeutic adherence (19.2\%) and a higher prevalence of high adherence $(30.8 \%)$. This may be due to the fact that the sample consisted of patients with apparent $\mathrm{RH}$ followed in a reference clinic, so that a stronger belief in the severity of the disease and need for medications may have contributed to better adherence..$^{24}$ Nevertheless, a considerable portion of the individuals did not have full 
adherence to pharmacological treatment, which may also have influenced the high mean SBP.

In the present study, men showed higher adherence to drug treatment. This finding corroborates the systematic review conducted by Hope et al. with individuals using statins, in which being a man was a predictor of better therapeutic adherence. ${ }^{26}$ However, the literature shows different results regarding the association between sex and adherence to pharmacological treatment: women showed greater adherence to the antihypertensive treatment regimen in a study conducted in Jordan, ${ }^{27}$ while there was no statistical difference between the sexes in individuals from rural Vietnam. ${ }^{28}$ These findings may be indicative that cultural and social factors have an important contribution to therapeutic adherence found in different countries.

De La Sierra et al., ${ }^{29}$ analyzed a large Spanish cohort of individuals treated for $\mathrm{RH}$, finding a prevalence of $12.2 \%$ of $\mathrm{RH}$; after investigating the data regarding ambulatory blood pressure measurement (ABPM) of these patients, it was found that in $37.5 \%$ of the cases, the ineffectiveness of the treatment was due to the white coat effect. ${ }^{29}$ Considering the relevance of the white coat effect, the authors and the current guidelines for the management of SH point to ABPM as a valuable tool in the diagnosis of true $\mathrm{RH}$, being the next propaedeutic step to be adopted in patients with apparent $\mathrm{RH}$, as in the case of the present study. 8,12,13,30

Because it is a cross-sectional study, there are inherent limitations to this type of research design. The number of individuals may not have been sufficient to demonstrate a statistically significant difference between the pressure levels of the groups of high and low therapeutic adherence and the performance of a multivariate analysis could reveal factors that better influence adherence. Adherence to nondrug therapy was not assessed. Furthermore, the use of indirect methods to assess medication adherence, such as MMAS-8, is vulnerable to memory bias, so that the answers given may not be reliable to the individual's real behavior.

Since no ABPM data were obtained, the study was not able to accurately distinguish between pseudoresistant patients and patients with actual RH. A comparison of the results of black patients with those of individuals who did not declare themselves as African-Brazilians could also have been considered.

It is evident that resistance to treatment with antihypertensive drugs is multifactorial. As evidenced in the literature, the appropriate choice of antihypertensive drugs, as well as the strengthening of the doctor-patient bond for better adherence to treatment, is essential for the management of RH. The importance of spironolactone in the treatment of $\mathrm{RH}$, especially in black people, should be disseminated among physicians and reported in national guidelines. The white coat effect should not be underestimated either, so that the relevance of ABPM in the diagnosis of true $\mathrm{RH}$ should also be emphasized in future Brazilian guidelines.

Future studies that aim to assess the understanding of the mechanisms by which socio-environmental issues influence blood pressure levels in the black population are essential for the creation of public health policies and for the guarantee of equity.

\section{Conclusion}

The present study showed that two-thirds of the individuals did not have high therapeutic adherence and some of them did not use the ideal triple regimen for the management of $\mathrm{RH}$, nor did they use full doses. These data culminated in the conclusion that most individuals included in the study were probably affected by pseudoresistance, which was initially diagnosed as apparent $\mathrm{RH}$.

\section{Potential Conflict of Interest}

No potential conflict of interest relevant to this article was reported.

\section{Sources of Funding}

There were no external funding sources for this study.

\section{Study Association}

This study is not associated with any thesis or dissertation work.

\section{Ethics Approval and Consent to Participate}

This study was approved by the Ethics Committee of the Hospital Ana Nery under the protocol number 08501212800000045. All the procedures in this study were in accordance with the 1975 Helsinki Declaration, updated in 2013. Informed consent was obtained from all participants included in the study. 


\section{Author Contributions}

Conception and design of the research: Macedo CRB, Aras-Jr R. Acquisition of data: Barletta PHAAS, Machado MAB, Almeida BL, Moreira JL, Almeida VF, Santos TSS, Silva TA, Nascimento YM. Analysis and interpretation of the data: Barletta PHAAS, Machado MAB, Almeida

\section{References}

1. Sarki AM, Nduka CU, Stranges S, Kandala N-B, Uthman OA. Prevalence of Hypertension in Low- and Middle-Income Countries. Medicine (Baltimore). 2015 Dec;94(50):e1959.

2. Go AS, Mozaffarian D, Roger VL, Benjamin EJ, Berry JD, Blaha MJ, et al. Heart Disease and Stroke Statistics - 2014 Update. Circulation. 2014 Jan 21;129(3):e28-292.

3. Lolio CA de, Pereira JCR, Lotufo PA, Souza JMP de. Hipertensão arterial e possíveis fatores de risco. Rev Saude Publica. 1993 Oct;27(5):357-62.

4. Lessa Í, Magalhães L, Araújo MJ, Almeida Filho N de, Aquino E, Oliveira MMC. Hipertensão arterial na população adulta de Salvador (BA) - Brasil. Arq Bras Cardiol. 2006 Dec;87(6):747-56.

5. Noblat ACB, Lopes MB, Lopes AA. Raça e lesão de orgãos-alvo da hipertensão arterial em pacientes atendidos em um ambulatório universitário de referência na cidade de Salvador Raça e Lesão de Órgãos-Alvo da Hipertensão Arterial em Pacientes Atendidos em um Ambulatório Universitário de Referência na Cidade de Salvador. Arq Bras Cardiol.2004;82(2):116-20.

6. Doroszko A, Janus A, Szahidewicz-Krupska E, Mazur G, Derkacz A Resistant Hypertension. Adv Clin Exp Med. 2016;25(1):173-83.

7. Braam B, Taler SJ, Rahman M, Fillaus JA, Greco BA, Forman JP, et al Recognition and Management of Resistant Hypertension. Clin J Am Soc Nephrol. 2017 Mar 7;12(3):524-35.

8. Wei F-F, Zhang Z-Y, Huang Q-F, Yang W-Y, Staessen JA. Resistant hypertension. Kardiol Pol. 2018 Jul 6;76(7):1031-42.

9. Malachias MVB, Souza WKSB, Plavnik FL et al. $7^{\text {a }}$ Diretriz Brasileira de Hipertensão Arterial. Arq. Bras. Cardiol. 2016 Sep; 107(3 Suppl 3).

10. Howard G, Prineas R, Moy C, Cushman M, Kellum M, Temple E, et al. Racial and Geographic Differences in Awareness, Treatment, and Control of Hypertension. Stroke. 2006 May;37(5):1171-8.

11. Hyman DJ, Pavlik V. Medication adherence and resistant hypertension. J Hum Hypertens. 2015 Apr 11;29(4):213-8.

12. Whelton PK, Carey RM, Aronow WS, Casey DE, Collins KJ, Dennison Himmelfarb C, et al. 2017 ACC/AHA/AAPA/ABC/ACPM/AGS/APhA/ ASH/ASPC/NMA/PCNA Guideline for the Prevention, Detection, Evaluation, and Management of High Blood Pressure in Adults: Executive Summary: A Report of the American College of Cardiology/ American Heart Association Task Force on Clinical Practice Guidelines. Hypertension. 2018 Jun;71(6):1269-324.

13. Williams B, Mancia G, Spiering W, Agabiti Rosei E, Azizi M, Burnier M, et al. 2018 ESC/ESH Guidelines for the management of arterial hypertension. Eur Heart J. 2018 Sep 1;39(33):3021-104.

14. Tu W, Eckert GJ, Hannon TS, Liu H, Pratt LM, Wagner MA, et al. Racial Differences in Sensitivity of Blood Pressure to Aldosterone. Hypertension. 2014 Jun;63(6):1212-8.

15. Kidambi S, Kotchen JM, Krishnaswami S, Grim CE, Kotchen TA Aldosterone Contributes to Blood Pressure Variance and to Likelihood of Hypertension in Normal-Weight and Overweight African Americans. Am J Hypertens.2009;22:1303-8.

16. Ahmed KS, Bogdanet D, Abadi S, Dineen R, Boran G, Woods CP, et al Rates of abnormal aldosterone/renin ratio in African-origin compared to European-origin patients: A retrospective study. Clin Endocrinol (Oxf). 2019 Apr;90(4):528-33.
BL, Moreira JL. Statistical analysis: Barletta PHAAS, Machado MAB. Writing of the manuscript: Barletta PHAAS, Moreira JL, Almeida VF, Machado MAB, Almeida BL. Critical revision of the manuscript for intellectual content: Santos TSS, Silva TA, Nascimento YM, Macedo CRB, Aras-Jr R.

17. Saha C, Eckert GJ, Ambrosius WT, Chun T-Y, Wagner MA, Zhao Q, et al. Improvement in Blood Pressure With Inhibition of the Epithelial Sodium Channel in Blacks With Hypertension. Hypertension. 2005 Sep;46(3):481-7.

18. Cai A, Calhoun DA. Resistant Hypertension: An Update of Experimenta and Clinical Findings. Hypertens (Dallas, Tex 1979). 2017;70(1):5-9.

19. Williams B, MacDonald TM, Morant S, Webb DJ, Sever P, McInnes G, et al. Spironolactone versus placebo, bisoprolol, and doxazosin to determine the optimal treatment for drug-resistant hypertension (PATHWAY-2): a randomised, double-blind, crossover trial. Lancet (London, England). 2015 Nov 21;386(10008):2059-68.

20. Liang W, Ma H, Cao L, Yan W, Yang J. Comparison of thiazide-like diuretics versus thiazide-type diuretics: a meta-analysis. J Cell Mol Med. 2017 Nov;21(11):2634-42.

21. Brasil. Ministério da Saúde. Secretaria de Ciência, Tecnologia e Insumos Estratégicos. Departamento de Assistência Farmacêutica e Insumos Estratágicos. Relação Nacional de Medicamentos Essenciais: RENAME. Brasilia;2017. 210p.

22. Kilsztajn S, Toshiaki G, Sugahara L, De E, Lopes S, Santos Petrohilos S. Concentração e distribuição do rendimento por raça no brasil. R. Econ. Contemp. 2005 ago; 9(2): 367-84.

23. Campello T, Gentili P, Rodrigues M, Rizzo Hoewell G. Faces da desigualdade no Brasil: um olhar sobre os que ficam para trás Faces of inequality in Brazil: a look at those left behind. Saúde.Debate. 2018;3(num.espec):54-66

24. Rajpura J, Nayak R. Medication Adherence in a Sample of Elderly Suffering from Hypertension: Evaluating the Influence of Illness Perceptions, Treatment Beliefs, and Illness Burden. J Manag Care Pharm. 2014 Jan;20(1):58-65.

25. Morisky DE, Ang A, Krousel-Wood M, Ward HJ. Predictive validity of a medication adherence measure in an outpatient setting. J Clin Hypertens (Greenwich). 2008 May;10(5):348-54.

26. Hope HF, Binkley GM, Fenton S, Kitas GD, Verstappen SMM, Symmons DPM. Systematic review of the predictors of statin adherence for the primary prevention of cardiovascular disease. Zeeb H, editor. PLoS One. 2019 Jan 17;14(1):e0201196

27. Al-daken LI, Eshah NF. Self-reported adherence to therapeutic regimens among patients with hypertension. Clin Exp Hypertens. 2017 Apr 3;39(3):264-70.

28. Nguyen T-P-L, Schuiling-Veninga CCM, Nguyen TBY, Vu T-H, Wright EP, Postma MJ. Adherence to hypertension medication: Quantitative and qualitative investigations in a rural Northern Vietnamese community. Bishopric NH, editor. PLoS One. 2017 Feb 1;12(2):e0171203.

29. de la Sierra A, Segura J, Banegas JR, Gorostidi M, de la Cruz JJ, Armario P, et al. Clinical Features of 8295 Patients With Resistant Hypertension Classified on the Basis of Ambulatory Blood Pressure Monitoring. Hypertension. 2011 May;57(5):898-902.

30. Judd E, Calhoun DA. Apparent and true resistant hypertension definition, prevalence and outcomes. J Hum Hypertens. 2014 Aug $16 ; 28(8): 463-8$ 